\title{
The Technical Information Service In the Stanford University Libraries
}

\author{
BY JACK POOLER and DAVID C. WEBER
}

A UNIVERSITY is created to advance and disseminate knowledge, primarily through formal instruction, but also through such activities as public lectures, conferences, advanced institutes, and publication programs. Library service to local industrial firms may be considered part of this support to the community at large. A university library is a local and often a national resource of great significance. Information is a valued asset, and a basic tenet of the democratic faith is the free availability of knowledge for the public welfare.

Even when privately financed a university has by its nature and mission a heavy obligation to the society which has created it, and the library's share in these obligations often becomes unusually burdensome and costly as a result of local circumstances. Thus, at least a half-dozen American university libraries have found requests from outside organizations to be intruding on primary obligations to students and faculty, and they have therefore set up financial charges to reimburse added expenditures, or have established rules restricting use to prevent exploitation.

As pointed out in September 1957 by E. M. Grieder, associate director of the Stanford University libraries, in his proposal for $A$ Business and Industrial Reference Service at Stanford, "The very rapid growth of industry, business, and other research activities in the Stanford area has created pressures and demands for which the old outside loan regulations are quite inadequate. The most pressing problems now are the immensely increased demand for books and journals, which results in the absence of important
Mr. Pooler is Director, Technical Information Service, and Mr. Weber is Assistant Director of Libraries, Stanford University. This paper was read to the Congresso Internazionale sulla Documentazione e l'Informazione Scientifico Tecnica in Rome in February 1964.

material from the Stanford libraries; and the considerable hidden cost of locating materials, processing loans, negotiating interlibrary loans, and other operations. Some departments of the university have expressed a strong dissatisfaction with the present practice for these reasons."

Stanford University met this situation by establishing in 1958 a separate library department, the technical information service (TIS), to handle the load from neighboring industrial and business firms. Until this time such requests and others from off-campus were handled either by interlibrary loan without charge or by photocopy services.

Before the TIS is described, an explanation of the typical industrial situation will serve to outline the needs met by this special library division. A typical business or industrial firm will have a library collection of journals, standard texts, technical reports, and reprints covering the firm's specific work, and the most relevant indexing and abstracting services. Some of the larger and older firms may have sizeable collections, but most have very small libraries varying markedly, depending on the corporation's conception of its own needs, especially as regards peripheral and older materials.

Speaking generally, an industrial library must be kept lean and of limited size because of the high cost of maintaining a 
large research collection with attendant staff salaries and expenses for housing the collection. Because of its apparent lack of profit-making ability, investors may criticize corporate policy which builds a major library as a long term investment. In many newer firms there is also a substantial hesitation due to the transitory nature of research projects. Firms like General Motors Corporation or Dow Chemical Company can have first-class libraries, because the size of the literature in relation to a comparatively stable product market can permit the library to be maintained on a small proportion of research and development funds. On the other hand, firms such as Lockheed Missiles and Space Company or International Business Machines Corporation, which are working in booming fields with a very high spread in the pertinent literature, would find it almost impossible to maintain a collection to satisfy all reasonable needs.

Beyond this there is increasing interdisciplinary growth, since as traditional problems are solved in physics, for example, new scientific approaches link physics with biology, chemistry, astronomy, and so forth and create new specialties with an exceedingly large growth in the literature. "To the historian looking backward from future time, this century will be memorable for .... the reunification of the sciences. ..."1

Since a university close to an industrial firm can offer its faculty as consultants, its public events as an enticement to research workers, and its library as an available support, many firms seek to locate near it. President Clark Kerr of the University of California at Berkeley has said that universities have become "bait" to be dangled in front of industry, with drawing power greater than low taxes or cheap power. Where Stanford University has property to lease, it has encouraged commercial, light industrial, and research

1 Joshua Lederberg, "Life Beyond the Earth," Stanford Today, Series 1, Number 7 (Winter 1963), [3]. groups to locate on it, with spectacular success. Such proximity increases the probability of outside requests on the university library.

As the volume of research grows under these circumstances, the university library may find these requests excessively burdensome. Some libraries have set up membership plans or substantial fees as a protective measure. In turn, industry may regard library access as a "right" for local residents, or it may claim discrimination when a firm is placed in a special category while private individuals are given free service or charged a nominal fee. Most industries accept substantial fees as proper payment for services rendered, however; they are used to paying for consultant services and are familiar with cost studies, overhead charges, and inventory expenses. Often their library services are kept deliberately at a minimum level, with plans to buy supplementary service.

The particular situation at Stanford is not unique. Rather it is typical of universities in several industrial areas, e.g., Boston, Cleveland, Houston, and Los Angeles. As a consequence of various local factors, special plans have been or are being established at institutions such as Massachusetts Institute of Technology, Princeton University, Western Reserve University, University of Houston, Rice University, Southern Methodist University, and California Institute of Technology.

Stanford University is located about halfway down a narrow peninsula at the north end of which is San Francisco. This area is densely settled and during and shortly after World War II there was an accelerated development of "clean industries," such as electronics and aerospace, and of government research throughout the peninsula, especially in the Stanford area. These firms, some long established and many newly created, were highly specialized, and their products required extensive research prior to production. 
In October 1958, the Stanford University libraries established the technical information service as a new department to fill specialized information needs of the three thousand research and development people in the industrial and governmentrelated organizations of the peninsula. Its general objective was to coordinate and develop the technical and scientific library resources and services of the research community in such a manner as best to serve the long-term interests of both industry and Stanford University. In the case of the latter, it was important also to minimize inconvenience to the faculty and student body by assuring that necessary materials be either on hand or retrievable on short notice.

Thus TIS became a research liaison point for industry located near Stanford University, providing áccess to library collections in the fields of economics, physical sciences, engineering, political science, life sciences, mathematics, earth sciences, and the many other subject fields which are essential ingredients of today's complex research needs.

Membership was restricted to an area within a fifty-mile radius of Stanford University on the theory that principal information sources outside this area should supply more distant industrial needs. Any local business or industrial organization needing research facilities qualified for membership. Membership was divided into two categories: regular members paying regular fees; and courtesy members, occasional users receiving introductory service at no charge for a period not to exceed six months or the completion of twenty-five library transactions.

Cost estimates for information retrieval are difficult to calculate, and as yet no entirely satisfactory means of determination had been established. In setting the charge for use of TIS, a combination of factors had to be considered.

First among these factors was direct operating cost. This is the cost of searching, paging, charging, record keeping, shelving, photocopying, mailing, etc., and can be estimated fairly well from anticipated operating expenses for salaries, equipment, and supplies.

Second-and far more difficult to assess-was the standby cost. This is the past and present cost of selecting, acquiring, cataloging, binding, housing, and otherwise maintaining the Stanford University libraries as an organized research facility, and of guaranteeing the maintenance of a collection capable of meeting outside research needs.

Also elusive was the determination of the cost needed to cover indirect TIS expenses for such items as quarters and administrative oversight and to prepare for future expansion. How rapidly would the membership list and the need for more varied service grow?

In view of these factors, a fee system seemed best adapted to the situation. The basic fee was established at five dollars per individual citation delivered as requested, either in the form of the book itself, or up to forty pages in photocopy. This amount was calculated to cover the direct cost of operating TIS, to contribute a fair amount toward the larger standby cost of maintaining and developing the Stanford University libraries (particularly the scientific and technical collections), and to allow for the future expansion of TIS.

Members could choose to be billed on a monthly or quarterly basis, or could deposit a credit account to be drawn against for TIS transactions. In all cases itemized accounting of charges was available.

A staff was organized which consisted of the part-time director, three library assistants (one responsible for searching out and retrieving library materials; another for taking telephone and mail orders, handling office files and billing; and the third for photocopying), and hourly student help for general assistance. Quarters were allocated in the centrally-located main library for the performance of office routines and photocopying procedures. 
Among services offered were the following:

Reading room use: Library privilege cards in the number needed were issued to company librarians who were in turn responsible for issuing them to authorized research personnel in their firms who needed to consult library materials in the reference collections, main stack, or branch libraries of the Stanford University libraries. Reference service was offered free of charge to TIS members.

Loans: Company librarians, or their authorized representatives, could arrange for the loan of library materials by telephone, mail, or in person. When possible, photocopies of requested material were supplied in order to retain the original on campus. Records of loans were to be maintained in the TIS office for recall follow-up, for billing purposes, and for statistics.

Reference service: Questions regarding bibliographical citations, serials, addresses, and other matters not involving extensive searching were to be answered free of charge by the TIS staff, as well as questions about availability of specific books and serials in the Stanford University libraries.

Interlibrary loan: Requests for library materials not in the Stanford University libraries could be channelled through TIS, which would obtain requested materials, if not contrary to lending regulations of the library holding the material. Upon delivery to requester the standard fee was charged.

Augmentation of resources: Company librarians were encouraged to make suggestions for the acquisition of library materials not in the Stanford University libraries. If related to teaching and research objectives, they could be purchased with TIS funds.

Special services: TIS was to explore the possibilities of obtaining for its members, on a cost basis, abstracting, translating, literature searching, compilation of bibli- ographies, extensive searching for information, and other special services.

The growth of TIS since its inception indicates that its original program was basically sound, although furnishing specific items by loan or photocopy has been the service most requested. During 1962/ 63 , nine firms has one hundred or more transactions each, accounting for all but about seventeen hundred of the total of 13,371 transactions.

To support this growth, TIS increased its staff, improved its equipment, and enlarged its quarters. The staff was strengthened by the addition of two professional librarians, relieving the director for planning and public relations work by providing supervision of operating procedures.

Equal emphasis was placed upon the improvement of equipment, since two major difficulties had been discovered. These were the means of photocopying and the means of transporting library materials from branches in the Stanford library system.

Photocopying was originally done by a Copease, a wet process machine which turned out good reproductions, but at a high cost in staff time, in machine maintenance, and in materials; and it was slow in processing. To improve this situation, a Xerox 914 Copier was added, although the Copease is still used for material containing tone illustrations. Use of the Xerox 914 suggests future possibilities for improving TIS service by offering a remote printout system, such as by use of Xerox LDX if bound volumes could be handled economically.

As for the problem of transporting library materials from the Stanford branch libraries for reproduction or mailing from the TIS office, the difficulty lay mainly in the size of the Stanford campus (thirtyfour branches widely distributed), and the number of volumes which need to be carried (currently, over thirteen thousand per year). At first this was handled by student help, but as the volume of ac- 
tivity grew, more skilled personnel was pressed into service, detracting from productive use of their specialized ability. As a partial solution to this problem a threewheeled delivery cycle, equipped with an enclosed detachable book truck, was designed and constructed. This has improved the service by increasing the speed and capacity of student help and by relieving trained personnel of the task of obtaining library materials for rush orders. However, future growth in volume may require the use of a motorized cart.

TIS now occupies three rooms on the third floor of the main library building. One room houses two librarians, the secretary-receptionist, and the bibliographic searcher. An adjacent room houses copying equipment and the operator. Across the hall is the office of the director, who spends four-fifths of his time serving as chief librarian of the science division of the university libraries.

Membership rules have been changed by the elimination of courtesy memberships. This was felt to be necessary because bibliographic work and record keeping for courtesy members assumed proportions which hindered rapid service to regular members, who recognized their responsibility in aiding the university financially toward the support of TIS. Further, TIS had become well known in the Stanford area and needed less introduction.

Effective September 1963, the original fee of five dollars per transaction was raised to six dollars, because of the increase during the past five years in direct operating costs.

TIS's service area has been enlarged to include the handling of interlibrary loan requests from all profit-making organizations outside the original area. Such requests, formerly handled by the interlibrary loan department, had become a serious burden, and the original fifty-mile limitation for TIS service was always an arbitrary boundary. Requests for library materials from profit-making organiza- tions are filled at the standard six dollar fee unless the need for photocopying exceeds the normal, in which case the published rates of the university's photographic department apply.

Lending to industries outside of the United States is handled under a new policy stating that, in lieu of sending originals, microfilms will be sent of lengthy items and full-size prints of shorter ones.

TIS recently cooperated in the compilation of The Union List of Serials Currently Received in the Science Libraries at Stanford. This list appeared in January 1964 with plans for subsequent annual revisions and will constitute a highly useful library tool for TIS members to whom copies are available at fifteen dollars per copy. Plans for the future include establishing certain services which were proposed in 1958 and which will be available on a cost basis to TIS members. These are abstracting, translating, literature searching, extensive information searching, and the compilation of bibliographies.

In retrospect, some minor difficulties exist as the TIS has been organized. In a library complex which has six major autonomous libraries outside its centralized administrative system, there is the possibility that one, because of local conditions, may establish different borrowing regulations. In Stanford's case, autonomous libraries have their own rules which TIS must observe. For example, they might even set up a separate service for industry. While not an impossible situation, this would not be economical use of staff or equipment. Thus industrial service with centralized facilities within the university seems distinctly preferable.

A difficulty then arises as to how to reimburse an autonomous library for use by TIS. Where the quantity is small, the financial adjustment is not worth the effort. When the quantity is considerable, it is desirable for TIS to return to each autonomous library the difference between its direct costs and the transaction 
charge in order that each library receive its stand-by portion. As yet the volume of TIS loans has not warranted such adjustments.

There is the possibility of an industrial representative presenting himself to a public service division of the library as an unattached researcher so as to obtain a library card for the nominal fee charged such individuals. No reputable firm would circumvent its obligation in this fashion, however, and an individual's corporate affiliation would be checked whenever the library staff had occasion to wonder about the purpose of his research. Innocent errors have occasionally occurred and have been corrected.

Since TIS is serving industry from within the academic environment, a dilemma may be said to exist where academic salaries for comparable positions are substantially below those in industry. This is more a theoretical than a real difficulty since the academic benefits of association and environment seem at least to balance the higher salaries. In point of fact, the balance is considerably in the university's favor in both quantity and quality of personnel.

In a general sense, TIS could not in the past respond or grow in measure with increased industrial requests. While the university library does not wish either the administrative burden or space problems of a mammoth TIS, such liabilities are small in comparison to the fair cost returns, to the protection against undue circulation loads, and to industrial good will and general public benefit resulting from TIS. Much of local industrial research is governmentally supported, so that as citizens interested in the economy of the country, librarians can be pleased with the economically beneficial information service offered to industries.

Because of these several points, a budgeting process which permits staff expansion and program growth based upon demand seems reasonable and desirable to both the university and to TIS mem- bers. Extensive literature searches, translations, and abstracting service may be begun or dropped in accordance with the demand for them by paying subscribers. This flexibility has no disadvantage to the university; rather it is advantageous because of its controlled nature. Control of staff, hours, conformance to procedures, etc., is a major benefit for the library and gives indirect protection against inconvenience to students and faculty.

In the past twenty years there has developed an industrial dependence on information sources which has affected university libraries to such a degree that several have made special provisions for it. Stanford's response was to create TIS. This industrial condition does not affect all universities, since their environments vary too greatly in both the quantity and type of industry. It seems certain that smaller libraries will not have heavy enough industrial loads for it to be worth creating a formal TIS, because they cannot furnish the information needed by industry in sufficient volume. Larger libraries will find it worthwhile only if in their vicinity there are one or more firms with active research programs.

These larger university libraries may indeed find the establishment of a TIS program in some form to be a necessity. It seems doubtful that these libraries can or will refuse service to industry entirely. It also seems dubious that an incorporated information service set up as an independent business venture could match a university TIS, since it would merely add the cost of a middleman in the information cycle. Finally, a central governmental library for service to science and industry seems impractical. This possibility deserves some comment however, especially since the British government has chosen this alternative.

A governmental library for science and industry in the United States would duplicate many reference and photocopy services now existing in the Library of Congress (for instance, its National Referral 
Center for Science and Technology), National Agricultural Library, National Library of Medicine, Department of Defense's Documentation Center, National Aeronautics and Space Administration's Office of Scientific and Technical Information, Atomic Energy Commission's Division of Technical Information Extension, and other information services.

But if universities fail to organize TIS or similar services on a scale sufficient to meet the information needs of all regions, industry may have to urge the federal government to create a super information agency, at least in the fields of science and technology. In contrast to the expense of a new centralized government-sponsored service with a dozen or more regional offices, there is the simplicity of the rapid and inexpensive TIS that would be possible from some fifty or more universities which are already strategically located in the United States.

A more realistic approach has recently been proposed in the Weinberg Report. ${ }^{2}$ It found "the specialized information center as a major key to the nationalization of our information system." Although some four hundred such centers in fields like nuclear spectroscopy or permafrost are said to exist in the United States, it was recommended "that more and better specialized centers be established . . . at public and private technical institutions." The committee felt that this means for transferring technical information might well become "dominant."

Such centers in highly specific fields can carry a great burden of technical information needs. There remain the needs that fall between such fields, that are more general in nature, or historical in emphasis. In these and other instances a university research library is in a unique position to facilitate the local flow of information.

\footnotetext{
2 U.S. President's Seience Advisory Committee. Science, Government, and Information: The Responsibilities of the Technical Community and the Government in the Transfer of Information; a Report. (Washington: G.P.O., 1963), pp. 3, 32-33.
}

This very point has awakened the interest of the National Science Foundation in developments at Stanford University and in studies at Johns Hopkins University and Southern Methodist University. It has also prompted the Council on $\mathrm{Li}$ brary Resources to finance a study by the Honnold library of a possible science information center in Claremont, California, an investigation which will include representatives of local industry.

Raynard C. Swank, director of the Stanford University libraries at the time that its TIS was created, has believed that local cooperative library services are a desirable pattern for the future. He commented three years ago that:

There can probably be no significant "information" service that is not based upon a major research library facility. On the peninsula, this means the Stanford library. This library can and should be changed and improved, but it cannot be bypassed except at the tremendous cost of duplicating its resources and services, whether by conventional or unconventional methods.

Second, any regional information system should take into account the needs of university research as well as of industrial and governmental research. Many "blue-sky" [i.e., unrealistic] proposals have thus far been oriented almost exclusively toward the latter; the university faculties have been ignored-and indeed have been little interested. The university ought to benefit substantially from any cooperative information program. ${ }^{3}$

The Stanford library is certain that the technical information service is distinctly beneficial to the university and to the local scientific and technological firms. It preserves the effectiveness of the library as a major instrument of academic teaching and research, and it extends the availability of information so as to strengthen productivity and facilitate new product research in American industry.

s R. C. Swank, letter to Provost F. E. Terman, November 8,1961 , p. 3 . 